\title{
EFFECT OF MORPHOI OGY OF $\gamma$ PHASE ON CREEP RESISTANCE OF A SINGLE CRYSTAL NICKEL-BASED SUPERALLOY, CMSX-4
}

\author{
Yoshihiro KONDO, Naoya KITAZAKI, Jirou NAMEKATA, Narihito OHI* and Hiroshi HATTORI* \\ The National Defense Academy, Yokosuka 239, Japan \\ *Ishikawajima-Harima Heavy Industries Co., Ltd. Tokyo 188, Japan
}

\begin{abstract}
$\underline{\text { Abstract }}$
The influence of the formation of a lamellar $\gamma-\gamma^{\prime}$ structure on creep resistance was investigated using the single crystal nickel-base superalloy, CMSX-4. The evolution of lamellae, or rafts was controlled by the duration of the prior-creep test conducted at $1273 \mathrm{~K}-160 \mathrm{MPa}$ up to $3.24 \times 10^{6} \mathrm{~s}$. Under these creep condition, the cuboidal $\gamma^{\prime}$ phase in the as-heat treated specimens turned to the rafted one through a transient creep stage. The stress enhanced creep tests were conducted at $1273 \mathrm{~K}-250 \mathrm{MPa}$ to evaluate creep resistance of the prior-creep tested specimens, and the minimum creep rates decided by the stress enhanced creep test were compared with that of the as-heat treated specimen. The minimum creep rates of the prior-creep tested specimens were always larger than that of the as-heat treated one. The dislocation substructure was not cormed in the cuboidal $\gamma^{\prime}$ and rafted $\gamma^{\prime}$, and was observed at the $\gamma / \gamma^{\prime}$ interface and $\gamma$ channel. The thickness of the $\gamma$ channel increased with increasing the prior-creep testing time. The correlation between the thickness of the $\gamma$ channel and the minimum creep rate in the stress enhanced creep test shows linear and is independent of the shape of $\gamma^{\prime}$. The TEM observation of specimens interrupted the stress enhanced creep test at the minimum creep rate showed that the radius of dislocation curvature was direclly proportional to the thickness of the $\gamma$ channel. Consequently, the loss of creep resistance through rafting of $\gamma^{\prime}$ is caused by the increase in the radius of dislocation curvature, not by the shape and the size of $\gamma^{\prime}$.
\end{abstract}

\section{Introduction}

Excellent creep resistance at high temperature of advanced single crystal nickel-based superalloys is derived from the large volume fraction more than $70 \%$ of intermetallic $\mathrm{Ni}_{3}(\mathrm{Al}, \mathrm{Ti})$ precipitate, known as $\gamma^{\prime}$, and from the regular array of the cuboidal $\gamma^{\prime}$ precipitate. By submitting to the creep deformation under the conditions of higher temperatures and relatively lower stresses, the cuboidal $\gamma^{\prime}$ precipitates in the [001] oriented single crystal turn their shape into platelets, which are called as the rafted structure and are oriented normal to the tensile stress axis ${ }^{1-5}$. This directional coarsening has been believed to enhance the creep resistance ${ }^{(6) 7)}$. Pearson et al. presented that the creep rupture life of a Ni-13Al-9Mo-2Ta(at\%) single crystal with rafted $\gamma^{\prime}$ was four times longer than that of the as-heat treated one ${ }^{6}$. In contrast to this, Nathal et al. indicated that a $\mathrm{Ni}-9.5 \mathrm{Cr}$ $5.5 \mathrm{Al}-1.2 \mathrm{Ti}-3.2 \mathrm{Ta}-10.0 \mathrm{~W}-1.0 \mathrm{Mo}(\mathrm{wt} \%)$ single crystal submitted to the creep defomation at $1273 \mathrm{~K}-148 \mathrm{MPa}$ for $1.5 \times 10^{5} \mathrm{~s}$ showed two times larger creep rate than the as-heat

$$
\text { Superalloys } 1996
$$

Edited by R. D. Kissinger, D. J. Deye, D. L. Anton,

A. D. Cetel, M. V. Nathal, T. M. Pollock, and D. A. Woodford

The Minerals, Metals \& Materials Society, 1996 treatcd onc ${ }^{8}$.

To evaluate creep resistance of the specimens subjected to the creep deformation, a stress enhanced creep test is applied to the prior creep tested specimen. To avoid the microstructural change, the stress enhanced creep test is preferable to the temperature enhanced creep test. Unfortunately, in both studies done by Pearson and by Nathal, temperatures in the stress enhanced creep test were reduced, thereby the enhanced stress secms to be high cnough to allow the dislocations to cut the cuboidal $\gamma$ ' precipitate. The effect of $\gamma^{\prime}$ morphology on creep resistance should be discussed under the conditions where dislocation climb in the $\gamma$ channel is predominant, because the prior-creep tests done to make the rafted specimens must be undertaken at the condition where the dislocation climb is predominant. Therefore the stress levels in the stress enhanced creep tests done by Pearson and Nathal are both unsuitable. Systematic rcsearch programs interrupting the creep tests at various times ranging from a transient creep stage to an accelerating creep stage have been desired to elucidate the correlation between the formation of the rafted structure and creep resistance.

In this study, the creep tests for the single crystals oriented in the [001] orientation were interrupted in the wide region ranging from a transient creep stage to an accelerating creep stage. The stress enhanced creep tests were performed only by increasing the applied stress without changing the testing temperature. The change in creep resistance of the specimens submitted to the creep was discussed by correlating with the change in $\gamma^{\prime}$ precipitate morphology to identify that the rafted structure of $\gamma^{\prime}$ precipitates acts as a creep strengthener or as a creep weakener.

\section{Experimental procedure}

Single crystals of CMSX-4 (analyzed composition in weight percent ; $6.4 \mathrm{Cr}, 9.3 \mathrm{Co}, 5.5 \mathrm{Al}, 0.9 \mathrm{Ti}, 6.3 \mathrm{Mo}, 6.2 \mathrm{Ta}, 6.2 \mathrm{~W}$, $2.8 \mathrm{Re}, 0.1 \mathrm{Hf}$, balance $\mathrm{Ni}$ ) were prepared in the form of bars $13 \mathrm{~mm}$ in diameter by directional solidificated casting. The exact orientations were determined by the Laue backreflection technique; longitudinal axes of single crystals selected for this study were within $5 \mathrm{deg}$ of the [001] orientation. After employing a eight steps solid solution treatment*1 and a two steps aging heat treatment ${ }^{* 2}$, the priorcreep tests were carried out at $1273 \mathrm{~K}$ and $160 \mathrm{MPa}$ (creep

*1 Solid solution treatment: $1550 \mathrm{Kx} 7.2 \mathrm{ks} \rightarrow 1561 \mathrm{Kx} 7.2 \mathrm{ks} \rightarrow$ $1569 \mathrm{Kx} 10.8 \mathrm{ks} \rightarrow 1577 \mathrm{Kx} 10.8 \mathrm{ks} \rightarrow 1586 \mathrm{Kx} 7.2 \mathrm{ks} \rightarrow$ $1589 \mathrm{Kx} 7.2 \mathrm{ks} \rightarrow 1591 \mathrm{Kx} 7.2 \mathrm{ks} \rightarrow 1594 \mathrm{Kx} 7.2 \mathrm{ks} \rightarrow \mathrm{GFC}$

$* 2$ Aging heat treatment: $1413 \mathrm{Kx} 21.6 \mathrm{ks} \rightarrow 1144 \mathrm{Kx} 72 \mathrm{ks} \rightarrow$ $\mathrm{AC}$ 


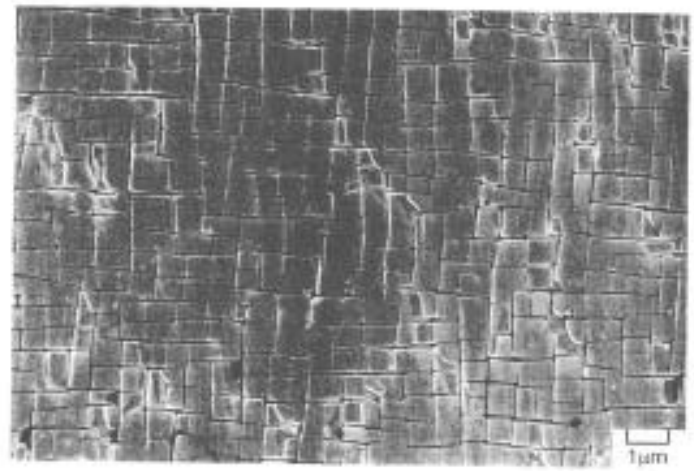

Fig. 1. Scanning electron micrograph of a single crystal nickel-based superalloy, CMSX-4.

rupture life is $3.60 \times 10^{6} \mathrm{~s}$ ), using the specimens with a gauge diameter of $8.0 \mathrm{~mm}$ and a gauge length of $50 \mathrm{~mm}$, and were interrupted at various times ranging from the transient creep stage to the accelerating creep stage. All the creep interrupted specimens were followed by cooling under load. The priorcreep tested specimens were re-machined into the specimens for the stress enhanced creep tests with a gauge diameter of $6.0 \mathrm{~mm}$ and a gauge length of $30 \mathrm{~mm}$ to remove the surface cracks. The stress enhanced creep tests were performed at $1273 \mathrm{~K}$ and $250 \mathrm{MPa}$. Creep strain was measured automatically through linear variable differential transformers (LVDT's) attached to extensometers. Microstructural examinations by SEM and TEM were carried out on specimens cut parallel to $(100)$ planes. Specimens for the SEM observation were prepared metallographically and electroetched with a supersaturated phosphoric acid-chromic acid solution. TEM foils were electropolished with a $5 \%$ solution of perchloric acid in alcohol. The volume fraction of the $\gamma^{\prime}$ phase was measured by use of image processing facilities. The ratio of the average width to the length in the $\gamma$ phase was defined as the aspect ratio and measured as a function of the priot creep testing time.

\section{Results}

\section{Microstructure of the as-heat treated specimen}

The microstructure of the as-heat treated specimen of CMSX4 is shown in Fig. 1. No eutectic $\gamma$ phase was observed and the cuboidal $\gamma^{\prime}$ phase was regularly present in the $\gamma$ matrix. The average edge length of the cuboidal $\gamma^{\prime}$ particles was controlled to be about $0.5 \mu \mathrm{m}$ and the width of the $\gamma$ channel was estimated approximately $0.09 \mu \mathrm{m}$.

\section{Prior-creep test}

The creep rate-time curve in the prior-creep test at $1273 \mathrm{~K}$ $160 \mathrm{MPa}$ of the as-heat treated specimen is shown in Fig. 2 . The open circles correspond to time where the prior-creep tests were interrupted to prepare the specimens for the stress enhanced creep test. The minimum creep rate was attained at about $10^{\circ} \mathrm{s}$, and the prior-creep testing time extended over a wide range from the latter half of the transient creep stage to the late accelerating creep stage.

\section{Microstructure of the prior-creep tested specimens}

The scanning electron micrographs of the specimens priorcreep tested for $1.08 \times 10^{\circ}$ and $3.24 \times 10^{\circ}$ s are shown in Fig. 3. The $\gamma$ phase coalesced with each other and the lamellar $\gamma-\gamma$ structures, that is rafted $\gamma$ structures, formed perpendicular

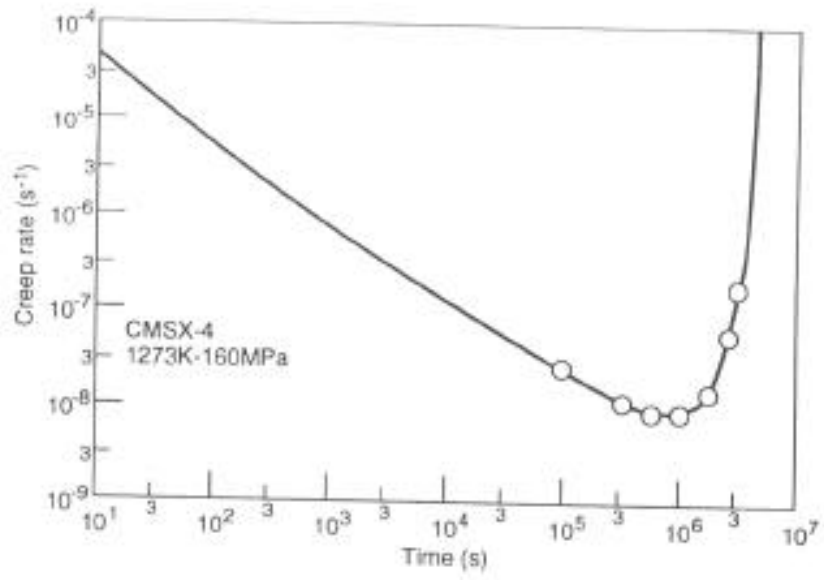

Fig. 2. Creep rate-time curve of the specimen crept at $1273 \mathrm{~K}$ $160 \mathrm{MPa}$. The open circles correspond to time where tests were interrupted for the microstructural examination and stress enhanced creep test.
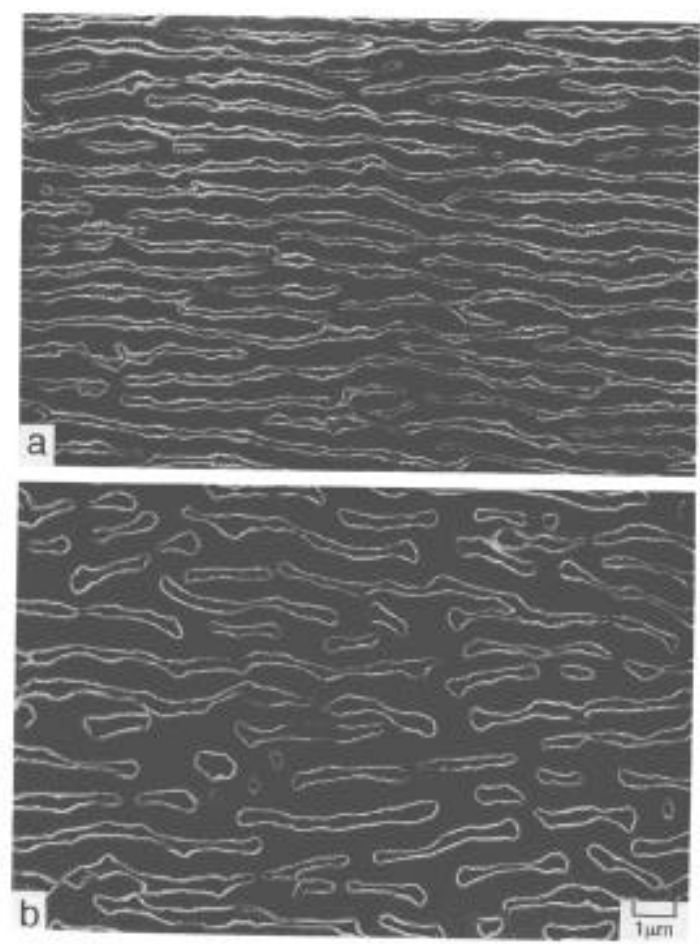

Fig. 3. Scanning electron micrographs of the specimens priorcreep tested at $1273 \mathrm{~K}-160 \mathrm{MPa}$ for (a) $1.08 \times 10^{\circ}$ and (b) $3.24 \times 10^{6} \mathrm{~s}$. Stress axis is vertical on these photos. 


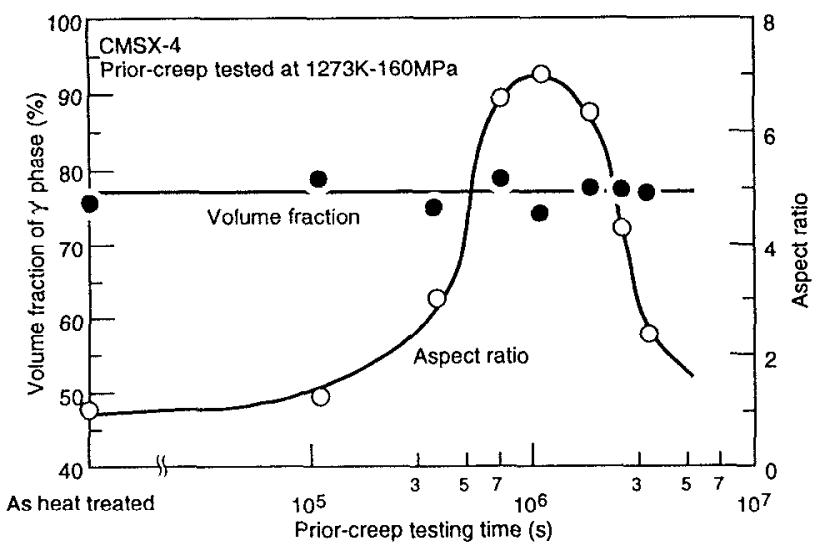

Fig. 4. Changes in the volume fraction and the aspect ratio of $\gamma^{\prime}$ of the prior-creep tested specimen with the prior-creep testing time at $1273 \mathrm{~K}$.

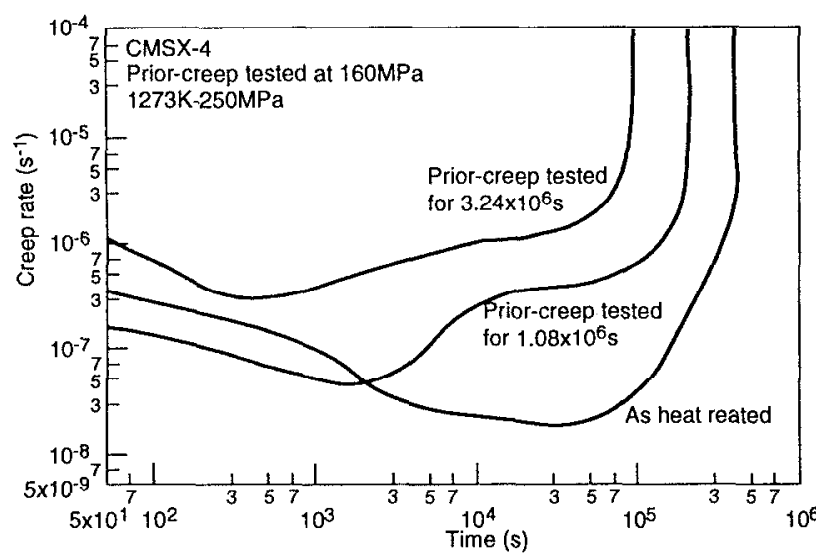

Fig. 5. Creep rate-time curves at $1273 \mathrm{~K}-250 \mathrm{MPa}$ of the specimens as-heat treated and prior-creep tested for $1.08 \times 10^{6}$ and $3.24 \times 10^{6} \mathrm{~s}$

to the stress axis was observed in the specimen prior-creep tested for $1.08 \times 10^{6} \mathrm{~s}$. However, the further coarsening of the $\gamma^{\prime}$ phase was detected in the specimen prior-creep tested for $3.24 \times 10^{6}$ s. And the lamellar $\gamma-\gamma^{\prime}$ structure was out of shape. The changes in the volume fraction and the aspect ratio of the $\gamma^{\prime}$ phase with the prior-creep testing time are shown in Fig. 4. The volume fraction of the $\gamma^{\prime}$ phase shown in the solid symbol was approximately $76 \%$, independent of the priorcreep testing time. Precipitation of the $\gamma^{\prime}$ phase seems to be finished through the pre-heat treatment. The aspect ratio of the $\gamma^{\prime}$ phase increased after subjecting the prior-creep tests beyond $1.08 \times 10^{5} \mathrm{~s}$, and reached to the maximum value of 7 at $1.08 \times 10^{6} \mathrm{~s}$. However, this maximum value of the aspect ratio did not remain, and soon the aspect ratio of the $\gamma^{\prime}$ phase decreased with increasing the prior-creep testing time and attained to about 2 at $3.24 \times 10^{6} \mathrm{~s}$. The lamellar $\gamma-\gamma^{\prime}$ structures showing the maximum aspect ratio were formed at the stage where creep rate reached the minimum. Therefore, the lamellar structure was defined as the unstable structure, and the change in the shape of $\gamma^{\prime}$ phase was proceeding with the prior-creep testing time through the accelerating creep stage.

\section{Stress enhanced creep test}

The creep rate-time curves at $1273 \mathrm{~K}-250 \mathrm{MPa}$ of the specimens as-heat treated and prior-creep tested for $1.08 \times 10^{6}$ and $3.24 \times 10^{6} \mathrm{~s}$ are shown in Fig. 5. The minimum creep rate of the specimen prior-creep tested for $1.08 \times 10^{6} \mathrm{~s}$ was about three times that of the as-heat treated one. And the minimum creep rate of the specimen prior-creep tested for $3.24 \times 10^{6} \mathrm{~s}$ showed twenty times larger value than that of the as-heat treated one.

The minimum creep rates obtained by the stress enhanced creep test were plotted as a function of the prior-creep testing time in Fig. 6. The minimum creep rate of the prior-creep tested specimens increased gradually up to $3 \times 10^{6}$ s with increasing the prior-creep testing time. Namely, the minimum creep rate of the specimen prior-creep tested for $7 \times 10^{5}$ to $2 \times 10^{6} \mathrm{~s}$ with the lamellar $\gamma-\gamma^{\prime}$ structures was three to five times that of the as-heat treated one with the cuboidal $\gamma^{\prime}$ phase. And the minimum creep rate of the specimen prior-creep tested for $3.24 \times 10^{6} \mathrm{~s}$ when the lamellar $\gamma-\gamma^{\prime}$ structures was out of shape, showed twenty times that of the as-heat treated one. Therefore, creep resistance of CMSX-4 decreased remarkably with increasing the prior-creep testing time.

\section{Discussion}

In general, the loss of strength of the polycrystalline heatresistant alloys due to high temperature creep is thought to result from mechanical damage such as initiation and propagation of cracks at grain boundary ${ }^{910}$. CMSX-4 used in this study, however, is the single crystal alloy and the surface layer of $1 \mathrm{~mm}$ in thickness of the prior-creep tested specimens was eliminated by re-machining after the priorcreep tests. The rupture elongation of the prior-creep tested specimens was constant, independent of the prior-creep testing time. Therefore, it was difficult to interpret that the loss of creep resistance due to the prior-creep test caused by mechanical damage. On the other hand, it was reported that the loss of strength of the polycrystalline heat-resistant alloys due to high temperature creep was attributed to deterioration such as degradation of deformation resistance caused by coalescence and coarsening of carbides and precipitation of

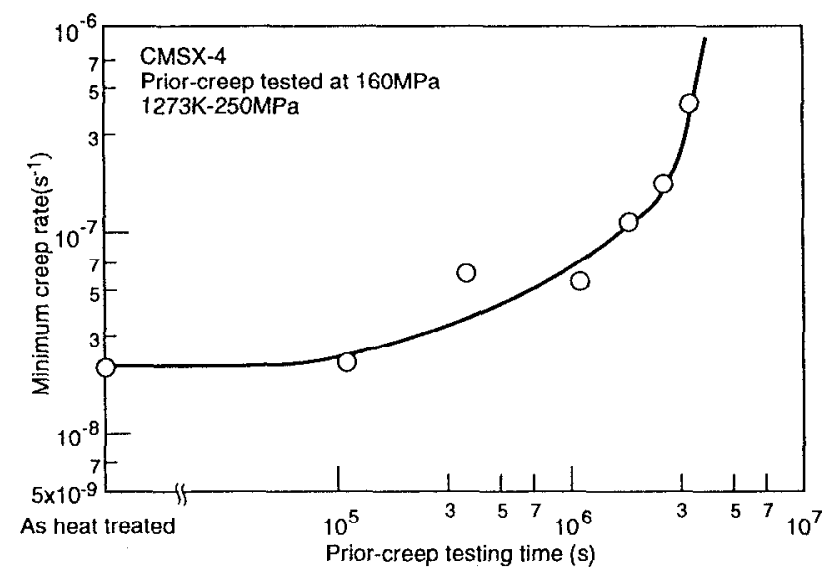

Fig. 6. Change in the minimum creep rate at $1273 \mathrm{~K}-250 \mathrm{MPa}$ of the as-heat treated and the prior-creep tested specimens with the prior-creep testing time. 


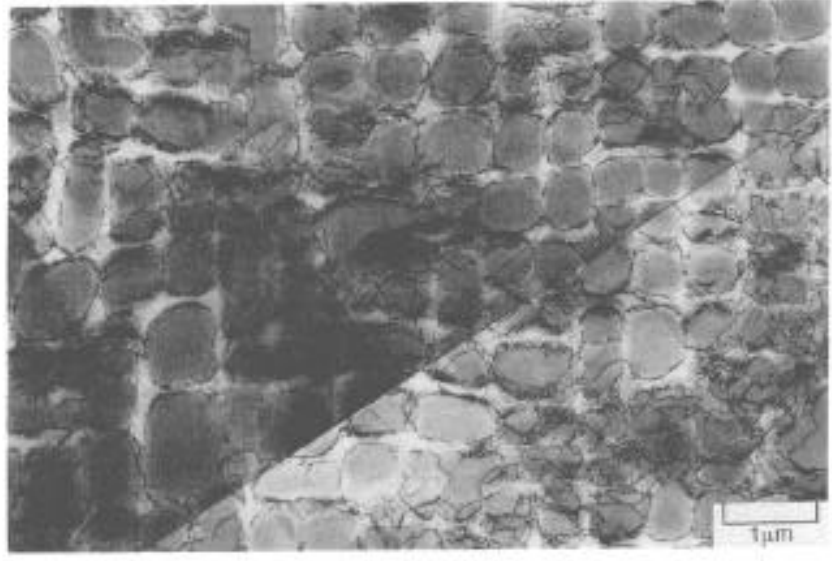

Fig. 7. Transmission electron micrograph of the as-heat treated specimen crept up to the minimum creep rate at $1273 \mathrm{~K}-250 \mathrm{MPa}$. Stress axis is vertical on this photo.

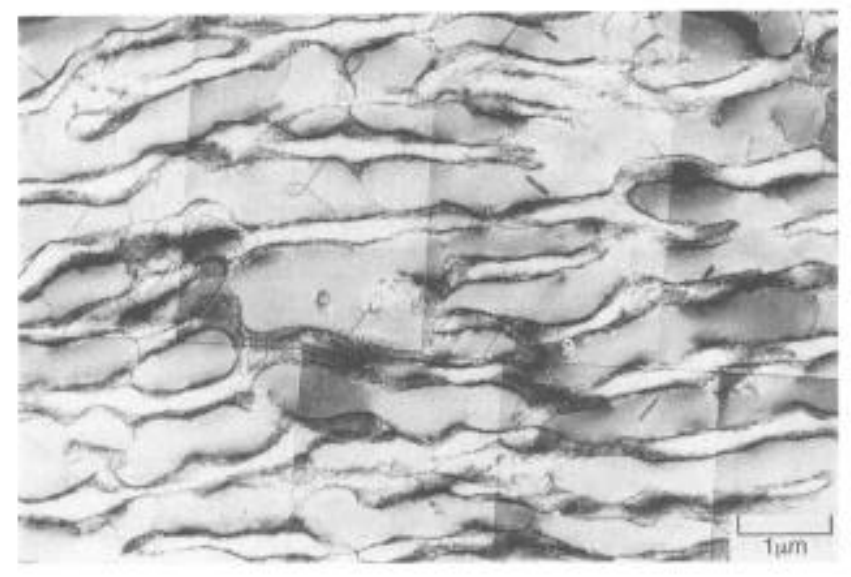

Fig. 8. Transmission electron micrograph of the specimen prior-creep tested for $1.08 \times 10^{\circ} \mathrm{s}$ and erept up to the minimum creep rate at $1273 \mathrm{~K}-250 \mathrm{MPa}$. Stress axis is vertical on this photo.

the TCP phase such as the sigma phase $\mathrm{e}^{1+20}$. The loss of creep resistance of the prior-creep tested specimens in this study was thought to result from deterioration based on the structural changes which take place uniformly over the whole structure. The loss of creep resistance due to the prior-creep tests appears to be attributed to the formation of the lamellar $\gamma-\gamma$ structures. Therefore, substructural examinations by transmission electron microscopy were carried out on the asheat treated and the prior-creep tested specimens interrupted the stress enhanced creep test at the time showing the minimum creep rate.

The transmission electron microstructure of the as-heat treated specimen interrupted the stress enhanced creep test at the time showing the minimum creep rate is shown Fig. 7. where the electron beam direction, B, was close to [100].
Few dislocations were observed in the $\gamma$ matrix and a small number of dislocations were present on the $\gamma / \gamma^{\prime}$ interface. The transmission electron microstructure of the specimen prior-creep tested for $1.08 \times 10^{\circ} \mathrm{s}$ and interrupted the stress enhanced creep test at the time showing the minimum creep rate, which was about five times that of the as-heat treated one, is shown in Fig. 8, where $B=[100]$. The dark regions were locally formed in the $\gamma$ matrix and was derived from the dislocation density. A number of dislocations were observed on the $\gamma / \gamma^{\prime}$ interface.

The transmission electron microstructure of the specimen prior-creep tested for $3.24 \times 10^{\circ} \mathrm{s}$ and interrupted the stress enhanced creep test at the time showing the minimum creep rate, which was about twenty times that of the as-heat treated one, is shown in Fig, 9, where $\mathrm{B}=[100]$. In the $\gamma$ matrix, the dark regions were also observed. By comparing the area of the dark region with that of the specimen prior-creep tested for $1.08 \times 10^{6}$ s, the dark region increased with increasing the prior creep testing time. A number of dislocations were also

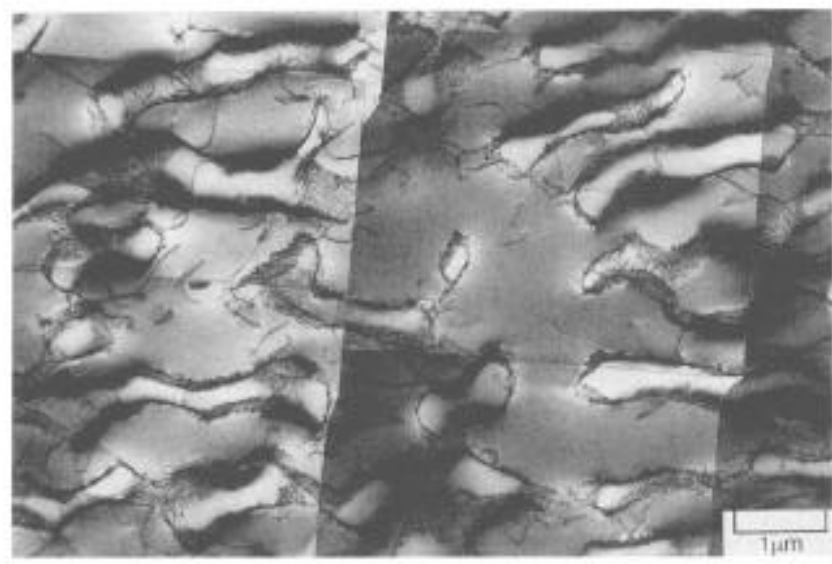

Fig. 9. Transmission electron micrograph of the specimen prior-ercep tested for $3.24 \times 10^{5}$ s and crept up to the minimum creep rate at $1273 \mathrm{~K}-250 \mathrm{MPa}$. Stress axis is vertical on this photo.

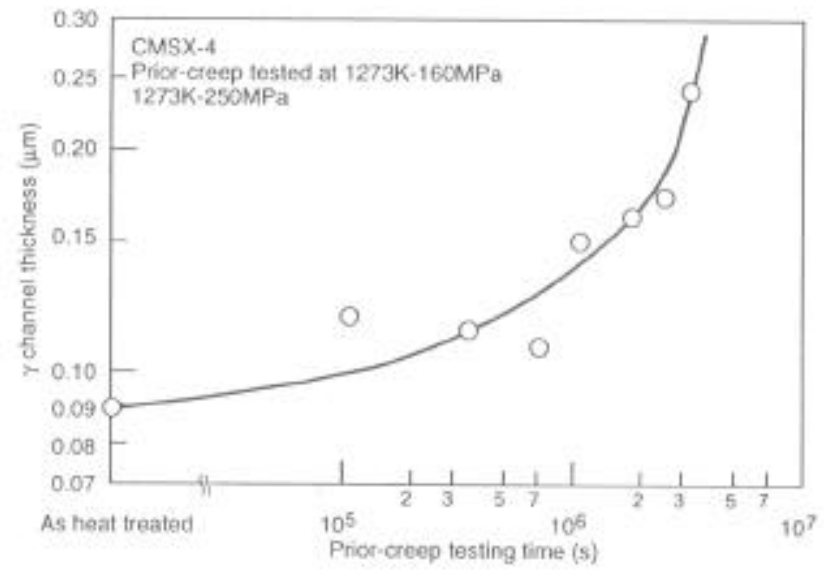

Fig. 10 Change in the $\gamma$ channel thickness of the specimens as-heat treated and the prior-creep tested with the prior-creep testing time. 


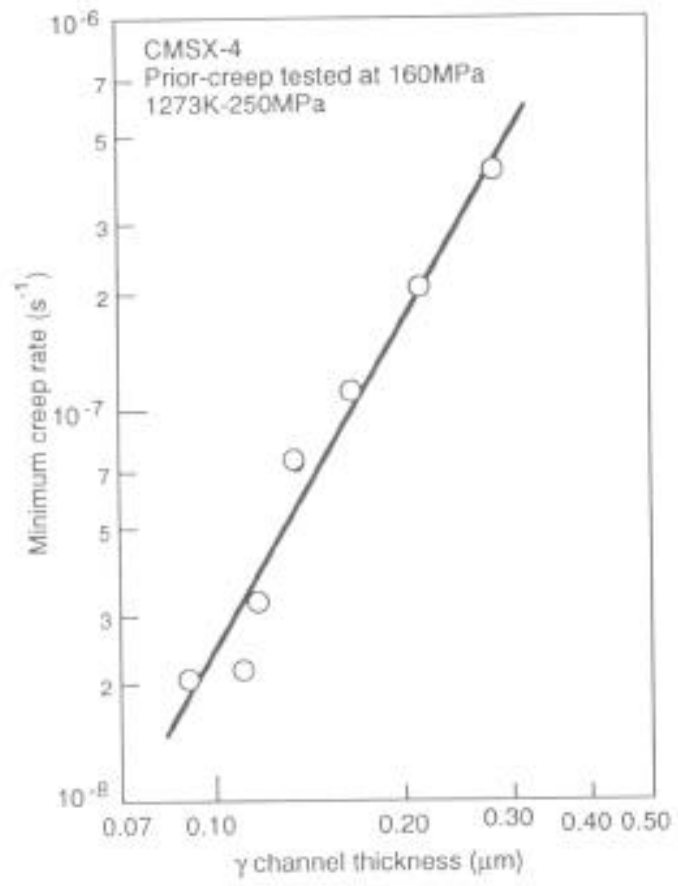

Fig. 11. Relation between the minimum creep rate and the $\gamma$ channel thickness of the as-heat treated and the prior-creep tested specimens

present on the $\gamma / \gamma^{\prime}$ interface. From the results that few dislocations existed within rafted $\gamma^{\prime}$, it was supposed that the creep deformation within the $\gamma$ channel was predominant. compared with the rafted $\gamma^{\prime}$. So, the movement of the dislocation within the thin $\gamma$ channel appeared to be strongly restricted. From the SEM observation of the specimens asheat treated and prior-creep tested for $1.08 \times 10^{\circ}$ and $3.24 \times 10^{\circ} \mathrm{s}$ as shown in Figs. 1 and 3, the $\gamma$ channel thickness seems to increase with increasing the prior-creep testing time. Releasing the dislocations from the restriction of the thin $\gamma$ channel through increasing the $\gamma$ channel thickness seems the substantial mechanism to increase the creep rate. The $\gamma$ channel thickness was measured on the as heat treated and the prior-creep tested specimens.

The $\gamma$ channel thickness of the as heat treated and the priorcreep tested specimens interrupted at the time showing the minimum creep rate was plotted as a function of the priorcreep testing time as shown in Fig. 10. The specimens subjected the longer prior-creep tests provide the thicker $\gamma$ channel. The $\gamma$ channel thickness of the specimens prior-ereep tested for $2 \times 10^{6}$ and $3 \times 10^{\circ} \mathrm{s}$ were approximately twice and three times that of the as-heat treated one with the cuboidal $\gamma$ phase, respectively.

The minimum creep rate of the prior-creep tested specimens was plotted as a function of the $\gamma$ channel thickness, as indicated in Fig. 11. The correlation between the minimum creep rate and the $\gamma$ channel thickness showed linear. independent of the shape of $\gamma$. Consequently, creep resistarice of single crystal nickel-based superalloys depends on the $\gamma$ channel thickness. The rcason was discussed why creep resistance decreased with an increase in the $\gamma$ channel thickness.

The high magnification transmission electron microstructures of the specimens prior-creep tested for $1.08 \times 10^{5}, 1.08 \times 10^{\circ}$ and $3.24 \times 10^{6} \mathrm{~s}$ are shown in Fig. 12, where $\mathrm{B}=[100]$. The bent dislocation with the small radius of curvature was observed within the $\gamma$ channel of the specimen prior-creep tested for $1.08 \times 10^{9} \mathrm{~s}$. The radius of dislocation curvature of the specimen prior-creep tested for $1.08 \times 10^{4} \mathrm{~s}$ was larger than that of the specimen prior-creep tested for $1,08 \times 10^{5}$ s and smaller than that of the specimen prior-tested for $3.24 \times 10^{5} \mathrm{~s}$. The radius of dislocation curvature secms to increase with an increase in the prior-creep testing time. It is well known that

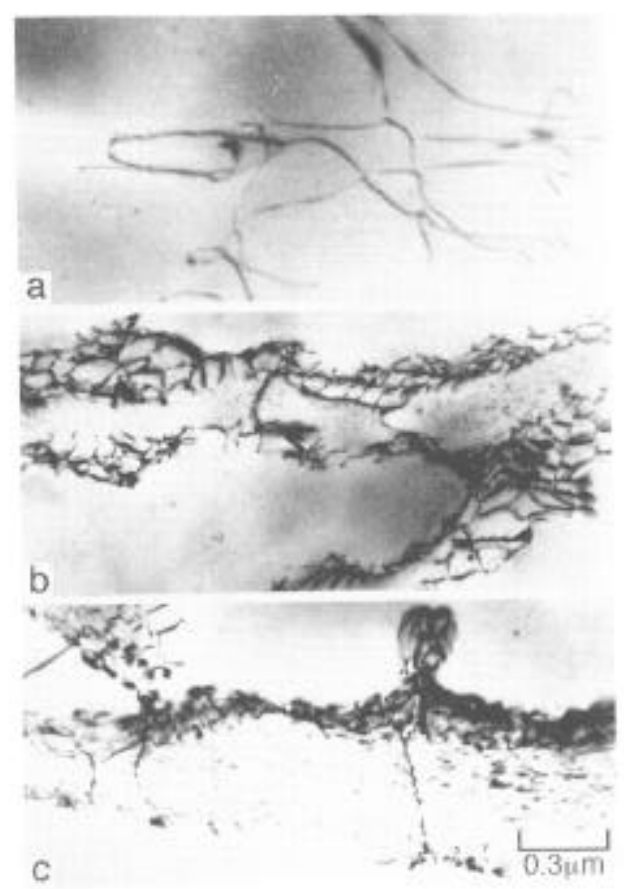

Fig. 12. High magnification transmission electron micrographs of the specimens prior-creep tested for (a) $1.08 \times 10^{5}$, (b) $1.08 \times 10^{6}$ and (c) $3.24 \times 10^{5} 5$ and crept up to the minimum creep rate at $1273 \mathrm{~K}-250 \mathrm{MPa}$

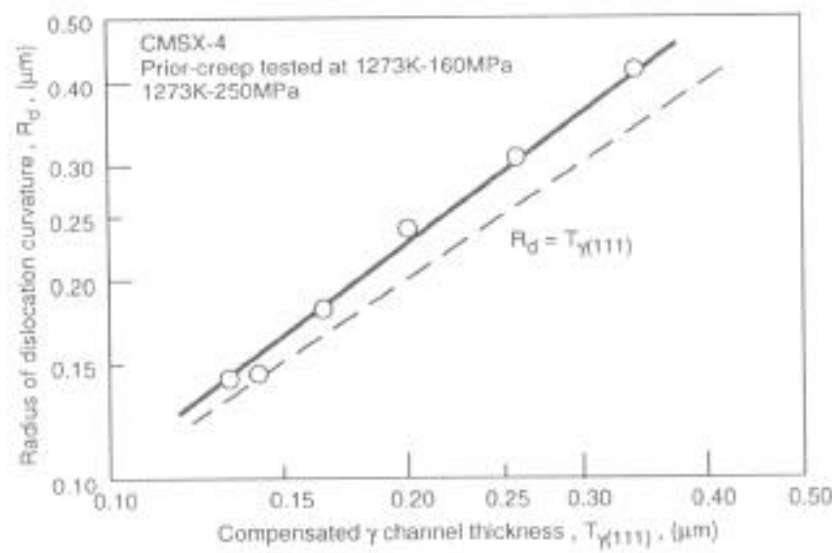

Fig. 13. Relation between the radius of dislocation curvature and the compensated $\gamma$ channel thickness of the as-heat treated and the prior-creep tested specimens. 


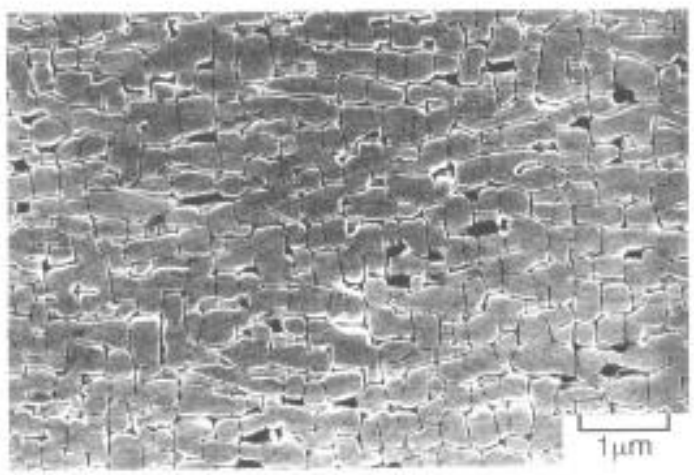

Fig. 14. Scanning electron micrograph of a single crystal nickel-based superalloy. CMSX-4 with the fine $\gamma$ phase.

an applied shear stress. $\tau$, is inversely proportional to the radius of dislocation curvature, $R_{\mathrm{d}}$, as shown in the following equation : $\tau=A / R_{\text {e }}$ if the dislocation is bent in the slip plane by an applied shear stress'13). The smaller radius of dislocation curvature needs the greater applied shear stress. It can be speculated that as the radius of dislocation curvature increases with an increase in the prior-creep testing time, the applied shear stress decreases and then the creep rate increases. The measurements of the radius of dislocation curvature were made on the stress enhanced creep tested specimens sectioned parallel to (111) planes which are the slip planes of fec metals.

The relation between the radius of dislocation curvature and the $\gamma$ channel thickness is shown in Fig. 13 where the $\gamma$ channel thickness was converted to the spacing between two neighboring $\gamma$ precipitates on (111) planes. The radius of dislocation curvature was directly proportional to the $\gamma$ channel thickness. From these results, it was concluded that creep resistance of single crystal nickel-based superalloys depends on the radius of dislocation curvature which is based on the $\gamma$ channel thickness.

To confirm the above results, a similar investigation is made on the single crystal nickel-base superalloy, CMSX.4, with the fine $\gamma^{\prime}$ phase which was obtained by a two steps aging heat treatment for $\gamma^{\prime}$ refining $(1323 \mathrm{~K} \times 21.6 \mathrm{ks} \rightarrow 1144 \mathrm{~K} \times 72 \mathrm{ks}$ $\rightarrow$ Watet quench) after a standard cight steps solid solution treatment and the results of the fine- $\gamma^{\prime}$ specimen are compared with those of the standard $-\gamma$ one.

The microstructure of the fine- $\gamma$ ' specimen in the as-heat treated condition is shown in Fig. 14. The cuboidal $\gamma$ ' phase was regularly present in the $\gamma$ matrix. The average edge length of the cuboidal $\gamma$ particles was shorter and the $\gamma$ channel thickness was thinner than those of the standard- $\gamma$ CMSX-4 which was shown in Fig. I.

The $\gamma$ channel thickness of the fine- $\gamma^{\prime}$ specimen was plotted as a function of the prior-creep testing time compared with that of standard- $\gamma^{\prime}$ specimen, as shown in Fig. 15. The $\gamma$ channel thickness of the as-heat treated specimens with fine $\gamma$ was approximately $2 / 3$ of that of the as-heat treated one with standard $\gamma^{\prime}$. The both specimens subjected the longer prior-creep tests provided the larger $\gamma$ channel thickness. The magnitude of the increase in the $\gamma$ channel thickness of the fine- $\gamma$ ' specimens with an increase in the prior-ereep testing time was larger than that of standard- $\gamma$ specimen, and by the prior-creep test for $2.52 \times 10^{6} \mathrm{~s}$, the $\gamma$ channel thickness of the fined- $\gamma$ specimen was approximately equal to that of the standard $\gamma$ specimen.

The minimum creep rate of the fine- and the standard- $\gamma$ specimens obtained by the stress enhanced creep test at $1273 \mathrm{~K}-250 \mathrm{MPa}$ was plotted as a function of the prior-creep testing time as shown in Fig. 16. The minimum creep rate of the as-heat treated specimens with fine $\gamma^{\prime}$ was approximately $1 / 10$ of that of the as-heat treated one with standard $\gamma$. The minimum creep rate of the fine- and the standard- $\gamma^{\prime}$ specimens increased with increasing the prior-creep testing time. The increasing ratio of the minimum creep rate with increasing the prior-creep testing time in the fine- $\gamma^{\prime}$ specimen was larger than that of standard $-\gamma^{\prime}$ specimen, and the minimum creep rate of the fine- $\gamma$ specimen prior-creep tested for $2.52 \times 10^{6} \mathrm{~s}$ was approximately equal to that of the standard- $\gamma$ specimen. The minimum creep rate in the fine- and the standard- $\gamma$ specimens, was plotted as a function of the $\gamma$ channel

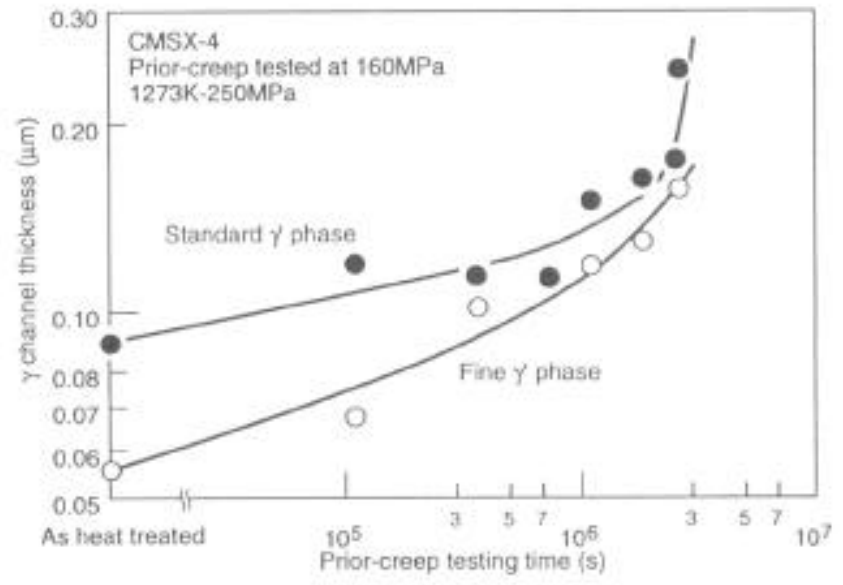

Fig. 15. Change in the $\gamma$ channel thickness of the fine- $\gamma^{\prime}$ specimen as-heat treated and prior-creep tested with the priorcreep testing time compared with that of the standard- $\gamma^{\prime}$ specimen.

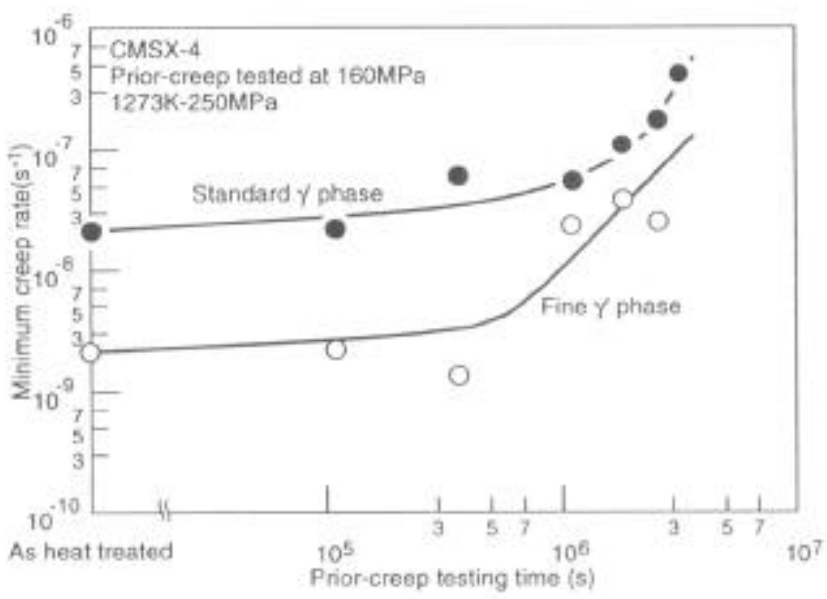

Fig. 16. Change in the minimum creep rate of the fine- $\gamma$ specimen as-heat treated and prior-creep tested with the priorcreep testing time compared with that of the standard $\gamma$ specimen. 


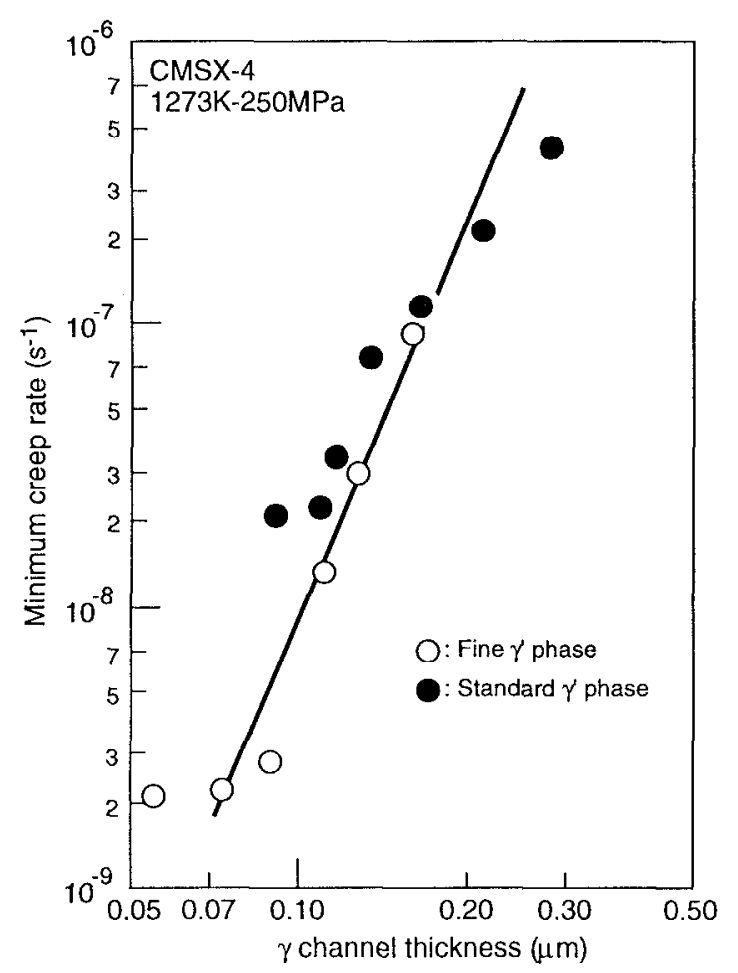

Fig. 17. Relation between the minimum creep rate and the $\gamma$ channel thickness of the as-heat treated and prior-creep tested specimens with the fine and the standard $\gamma^{\prime}$ phase.

thickness, as indicated in Fig. 17. The correlation between the minimum creep rate and the $\gamma$ channel thickness showed linear, independent of the shape and the size of $\gamma^{\prime}$. Consequently, creep resistance of single crystal nickel-based superalloys directly depends on the $\gamma$ channel thickness.

\section{Conclusions}

High temperature creep resistance of the prior-creep tested single crystal nickel based superalloy, CMSX-4, was investigated in connection with the morphology of the $\gamma^{\prime}$ phase. The results can be summarized in the following: 1) The $\gamma-\gamma^{\prime}$ lammelar structures were formed perpendicular to the stress axis during the transient creep stage, but regularity of the rafted $\gamma^{\prime}$ diminished during the long time prior-creep test.

2) The volume fraction of the $\gamma^{\prime}$ phase was constant independent of the prior-creep testing time. The aspect ratio of the $\gamma^{\prime}$ phase of the prior-creep tested specimens increased with an increase in the prior-creep testing time and achieved the maximum value 7 , and then it decreased to about 2 .

3) The minimum creep rate obtained by the stress enhanced creep test using the prior-creep tested specimens increased with an increase in the prior-creep testing time.

4) The TEM observation of specimens interrupted the stress enhanced creep test showed that the radius of dislocation curvature was directly proportional to the $\gamma$ channel thickness. 5) The $\gamma$ channel thickness increased with an increase in the prior-creep testing time and the correlation between the minimum creep rate and the $\gamma$ channel thickness showed lincar, independent of the shape and the size of $\gamma^{\prime}$.

6) It was concluded that the creep resistance of single crystal nickel-based superalloys depends on the radius of dislocation curvature which was based on the $\gamma$ channel thickness, independent of the shape and the size of $\gamma^{\prime}$.

\section{Reference}

1) J. K. Tien and R. P. Gamble, "Effects of Stress Coarsening on Coherent Particle Strengthening," Metall. Trans A, 3A(1972), 2157-2162

2) M. V. Nathal and L. J. Ebert, "Elevated Temperature Creep-Rupture Behavior of the Single Crystal Nickel-base Superalloy NASAIR 100," Metall, Trans A, 16A(1985), 427439

3) N. Kitazaki, Y. Kondo, J. Namekata, N. Ohi, and H. Hattori, "Creep Resistance of Single crystal Ni-based Superalloy, CMSX-4, at 1273K," 123rd Committee on Heat Resisting Metals and Allops Rep., 35(1994), 353-360

4) K. Ishibashi, Y. Kondo, J. Namekata, N. Ohi, and H. Hattori, "Effect of Tensile Orientation Rafting Structure of Gamma Prime Precipitales in Single Crystal Ni-base Superalloy CMSX-2," 123 rd Committee on Heat Resisting Metals and Alloys Rep., 34(1993), 165-172

5) K. Ishibashi, Y. Kondo, J. Namekata, N. Ohi, and H Hattori, "Long-term Creep Rupture Properties of Single Crystal Ni-based Superalloy, CMSX-4," 123rd Committee on Heat Resisting Metals and Alloys Rep., 37(1996), 1-10

6) D. D. Pearson, F. D. Lemkey and B. H. Kear, "Stress Coarsening of $\gamma^{\prime}$ and its Influence on Creep Properties of a Single Crystal Superalloy," Proc. of the 4th Int'l Conf. Superalloys 1980, (1980), 513-520

7) R. A. MacKay and L. J. Ebert, "The Development of $\gamma$ - $\gamma$ " Lamellar Structures in a Nickel-Base Superalloy during Elevated Temperature Mechanical Testing," Mctall. Trans A, 16A(1985), 1969-1982

8) M. V. Nathal, R. A. MacKay and R. V. Miner, "Influence of Precipitate Morphology on Intermediate Temperature Creep Properties of a Nickel-Base Superalloy Single Crystal," Metall. Trans A, 20A(1989), 133-141

9) D. A. Woodford, "Creep Damage and the Remaining Life Concept," J. Eng. Mater. Technol., 101(1979), 311-316

10) N. Shin-ya and S. R. Keown, "Correlation between Rupture Ductility and Cavitation in Cr-Mo-V Steels," Met. Sci., 13(1979), 89-93

11) K. R. Williams and B. Wilshire, "Effects of Microstructural Instability on the Creep and Fracture Behaviour of Ferritic Steels," Mater. Sci. Eng, 28(1977), 289-296

12) K. R. Williams and B. Wilshire: Mater. Sci. Eng., 38(1979), 199-210

13) C. J. Bolton, B. F. Dyson and K. R. Williams, "Metallographic methods of Determining residual Creep Life," Mater. Sci. Eng., 46(1980), 231-239

14) L.P. Stoter, Thermal Ageing Effects in AISI Type 316 Stainless Stecl," J. Mater. Sci., 16(1981), 1039-1051

15) J. M. Leitnaker and J. Bentley, "Precipitate Phases in Type321 Stainless Steel After Again 17 years at $\sim 600^{\circ} \mathrm{C}$," Metall. Trans A, 8A(1977), 1605-1613

16) J. H. Hoke and F. Eberle, "Experimental Superheater for steam at 2000Psi and 1250F-Report after 14,281 Hours of Operation," Trans. ASME, 79(1957), 307-317

17) Y. Kondo, T. Matsumura, J. Namekata, Y. Yamaguchi, M. Tanaka, and F. Hangai, "Dcgradation of SUS 304 by High Temperature Exposure and Recovering Heat-treatment 
18) M. Tanaka, F. Hangai, Y. Kondo, and J. Namekata, "Study on Microstructure and Mechanical Properties of SUS304 Used for a Long Time at Elevated Temperature," $123 \mathrm{rd}$ Committee on Heat Resisting Metals and Alloys Rep., 24(1983), 373-384

19) Y. Kondo, T. Matsumura, J. Namekata, M. Tanaka, and F. Hangai, "Effect of Recovery Treatment on the Mechanical Properties of SUS304 Serviced for Prolong Time at Elevated Temperature," 123rd Committee on Heat Resisting Metals and Alloys Rep., 26(1985), 133-139
20) Y. Yamaguchi, M. Tanaka, F. Hangai, Y. Kondo, and J. Namekata, "Microstructures and Mechanical Properties of SUS304 Serviced for Prolonged Time at 520 $610^{\circ} \mathrm{C}$," Trans. ISIJ., 24(1984), B-61

21) A. Kelly, and R. B. Nicholson, Strengthening Methods in Crystals(Ansterdan: Elsevier, 1971), 9

22) F. R. N. Nabarro, Theory of Crystal Dislocations(London: Oxford, 1967), 53

23) J. Weertman, and J. R. Weertman, ElementaryDislocation Theory(New York, NY: Macmillan, 1964) 